\title{
Robert W. Woody - A pioneer of protein circular dichroism spectroscopy
}

\section{Parvez I. Haris *}

Faculty of Health \& Life Sciences, De Montfort University, The Gateway, Leicester, UK

Circular dichroism (CD) spectroscopy is by far the most widely used technique for protein secondary structure analysis. A survey of the scientific literature will reveal that Robert Woody (Fig. 1) has undoubtedly been a pioneer in the elucidation of the relationship between CD and protein structure and

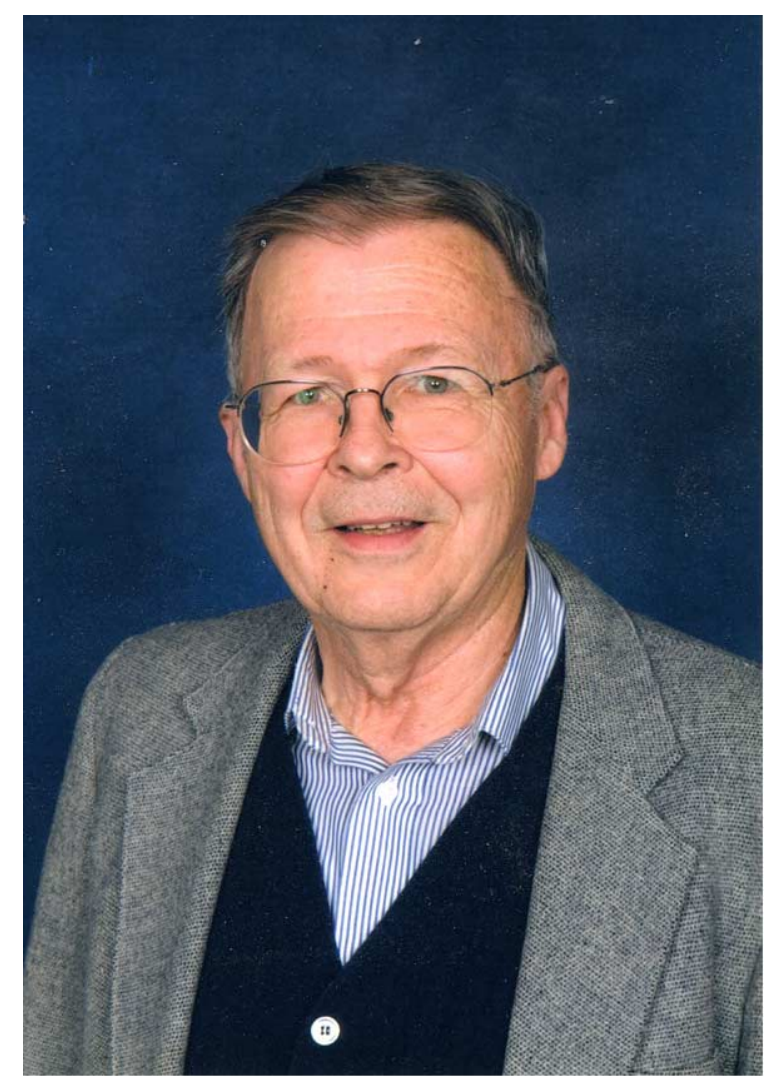

Fig. 1. Robert Woody. (Colors are visible in the online version of the article; http://dx.doi.org/10.3233/BSI-150103.)

\footnotetext{
*Address for correspondence: Faculty of Health \& Life Sciences, De Montfort University, The Gateway, Leicester, LE1 9BH, UK. E-mail: pharis@dmu.ac.uk.
} 
the application of CD to secondary structure analysis of proteins. The current issue of Biomedical Spectroscopy and Imaging contains an article by him on the evolution of CD spectroscopy [7].

Robert Woody is currently an emeritus Professor at the Department of Biochemistry and Molecular Biology, Colorado State University. He obtained his PhD from the University of California, Berkeley in 1962. His PhD supervisor, Ignacio (Nacho) Tinoco, was interested in applying optical rotatory dispersion (ORD) to study $\alpha$-helix formation in polypeptides. At that time, there were many unanswered questions in this field including the relationship between helix ORD and helix length. This was amongst a series of challenges that Robert Woody had to tackle during his PhD project. Robert Woody was successful in making significant contributions towards a basic understanding of the $\mathrm{CD}$ of the $\alpha$-helix [6]. $\mathrm{He}$ published his first paper on ORD of the $\alpha$-helix in 1960 [5]. More than half a century later, he continues to make ground breaking contributions in our understanding of the relationship between optical spectra and protein structure. For example, his most recent paper reports on the absorption and CD spectroscopic analysis of channelrhodopsins [3].

The numerous scientific research contributions of Robert Woody are highly appreciated by the scientific community. The impact of his research is particularly evident from an online tool (CDPro program package) for estimating secondary structure of proteins from CD spectra, which he produced with his colleague Narasimha Sreerama. This tool is widely used by researchers around the world and is available at the following website: http://lamar.colostate.edu/ sreeram/CDPro/. Indeed, the paper [4] describing this tool is the most cited paper in this field of research. One particular strength of the CDPro package is that it not only contains reference spectra of soluble proteins but also includes spectra of denatured proteins and integral membrane proteins.

Robert Woody is not only an outstanding research scientist but also a highly accomplished teacher. He has trained a large number of research scientists, some of whom are leaders in their area of research. I came to know of his research during my PhD project with Dennis Chapman [2] back in 1985 which involved structural studies of membrane proteins. During this period, I came to appreciate the excellent research contributions made by Robert Woody. One of his papers, which he published with his $\mathrm{PhD}$ student Mohammed Bazzi, was particularly useful for my own research since it applied both CD and infrared spectroscopy to characterise the structure of a membrane protein [1]. At that time it was one of the few studies of its type, making him one of first scientists to explore the use of CD spectroscopy for membrane protein structure analysis. Since then I have followed his work very closely. It was therefore indeed a great pleasure when he accepted my invitation to produce an article on the evolution of CD spectroscopy.

For over fifty years, Robert W. Woody has been passionately engaged in cutting-edge research activities that have advanced our understanding of CD spectra of proteins. I hope that he continues to maintain his dynamic and vigorous research program and further enrich the scientific community.

\section{References}

[1] M.D. Bazzi and R.W. Woody, Oriented secondary structure in integral membrane proteins. I. Circular dichroism and infrared spectroscopy of cytochrome oxidase in multilamellar films, Biophys. J. 48 (1985), 957-966.

[2] P.I. Haris, Dennis Chapman (1927-1999), Trends in Biochem. Sci. 25 (2000), 104-105.

[3] G. Pescitelli, H.E. Kato, S. Oishi, J. Ito, A.D. Maturana, O. Nureki and R.W. Woody, Exciton circular dichroism of channelrhodopsin, J. Phys. Chem. B 118 (2014), 11873-11885.

[4] N. Sreerama and R.W. Woody, Estimation of protein secondary structure from circular dichroism spectra: Comparison of CONTIN, SELCON, and CDSSTR methods with an expanded reference set, Anal. Biochem. 287 (2000), 252-260.

[5] I. Tinoco Jr. and R.W. Woody, Optical rotation of oriented helices. II. Calculation of the rotatory dispersion of the alpha helix, J. Chem. Phys. 32 (1960), 461-467. 
[6] R.W. Woody, The optical activity of helical molecules, PhD thesis, University of California, Berkeley, 1962.

[7] R.W. Woody, The development and current state of protein circular dichroism, Biomedical Spectroscopy and Imaging 4 (2015), 5-34. 